\title{
Severe osteogenesis imperfecta: case report
}

\author{
Osteogênese imperfecta na forma grave: relato de caso
}

\begin{abstract}
Fernando Bastos ${ }^{1}$, Liliana Thaureaux Perez ${ }^{2}$, Caridad Ponce de León Narváes 3 , Olívia Costa ${ }^{4}$, Rui Carlos Souto da Silva ${ }^{5}$, Joaquim Carlos Vicente Dias Van-Dunem ${ }^{6}$, Sandra Maria da Rocha Neto de Miranda ${ }^{7}$, Lemuel Bornelli Cordeiro ${ }^{8}$, Patrícia Conceição Silvia Maia ${ }^{9}$, Leonídia de Fátima Lopes Marques Airosa ${ }^{10}$, Aida de Menezes ${ }^{11}$
\end{abstract}

\begin{abstract}
The authors present a case of Osteogenesis Imperfecta, emphasizing the clinical and epidemiological characteristics, forms of classification and treatment of the disease. This is an important case not only to the knowledge of pediatricians and orthopedists, but also for other professionals involved with the problem. This article has been jointly described by the Departments of Pediatrics and Neonatology of the Girassol Clinic in Luanda Capital of the Republic of Angola, Africa.
\end{abstract}

Keywords: Osteogenesis imperfecta/classification; Osteogenesis imperfecta/ epidemiology; Osteogenesis imperfecta/therapy; Case reports

\section{RESUMO}

Os autores apresentam um caso clínico de Osteogenesis Imperfecta, dando ênfase às características clínicas, epidemiológicas, formas de classificação e tratamento da doença. Trata-se de um caso clínico importante para o conhecimento não só de pediatras e ortopedistas, mas também de outros profissionais envolvidos com o problema. 0 artigo foi descrito juntamente dos Serviços de Pediatria e de Neonatologia da Clínica Girassol, em Luanda, Capital da República de Angola, África.

Descritores: Osteogênese imperfeita/classificação; Osteogênese imperfeita/epidemiologia; Osteogênese imperfeita/terapia; Relatos de casos

\section{INTRODUCTION}

Osteogenesis imperfecta (OI) is a rare disease with estimated prevalence of $1 / 10,000$ to $1 / 20,000$ births. It is characterized by the presence of brittle bones and osteopenia ${ }^{(1)}$. Although it has been recognized as a disease since 17 th century, currently a number of important changes have been introduced on its concept. Traditionally, this disease was considered an affection only for one alteration in genes that produce collagen type I, which basically is constituted by four types (I to IV), according to classification by Sillence et al. (1979), based on cli nical and radiological features ${ }^{(2)}$ without possibility of curative clinical treatment. Therefore, with the introduction of current studies on molecular genetic analysis, the designation "ostegenesis imperfecta" became a group of disorders recognized as defects of quantitative and qualitative production in collagen synthesis, which originate a large clinical variability ${ }^{(3)}$. Although, several forms (type V to VIII) were identified and, at the same time, reasonable therapeutics possibilities capable to improve the course of the disease and quality of patient's life were introduced ${ }^{(3,4)}$. Is important to highlight that some authors suggest that types VII and VII must be excluded from the classification, because they are different in genetic criterions, however, they overlap types II-IV(4).

\footnotetext{
Study carried out at Neonatal ICU of Clínica Girassol, Luanda, Angola.

' MD, Neonatologist; Coordinator of Neonatal Unit of Clínica Girassol, Luanda, Angola.

${ }^{2} \mathrm{MD}$, Neonatologist of Neonatal ICU team of Clínica Girassol, Luanda, Angola.

${ }^{3} \mathrm{MD}$, Neonatologist of Neonatal ICU team of Clínica Girassol, Luanda, Angola.

${ }^{4} \mathrm{MD}$, Neonatologist of Neonatal ICU team of Clínica Girassol, Luanda, Angola.

${ }^{5} \mathrm{MD}$, Pediatric Surgeon of Clínica Girassol, Luanda, Angola.

${ }^{6}$ Professor of Teaching and Research Office of Clínica Girassol, Luanda, Angola.

${ }^{7}$ MD, Epidemiologist of Clínica Girassol, Luanda, Angola.

${ }^{8}$ Professor of Teaching and Research Office of Clínica Girassol, Luanda, Angola.

${ }^{9}$ Neonatal Nurse of Neonatal ICU of Clínica Girassol, Luanda, Angola; Master's Degree student in Health Communication at Universidade Aberta de Portugal, Portugal.

${ }^{10}$ First Year Resident in Pediatrics of Clínica Girassol, Luanda, Angola.

"MD, Pediatric Unit of Clínica Girassol, Luanda, Angola.

Corresponding author: Fernando Bastos - Rua Minas Gerais, 180.- CEP 122307-060 - Jacareí (SP), Brasil - Tel.: 11 3955-3444 - e-mail: fernandobbastos@yahoo.com.br

Received on May 24, 2010 - Accepted on 28/10/2010
} 
The importance of this disease has grown because it became part of differential diagnosis of battered-child syndrome cases, which requires adequate knowledge of pediatricians and health professionals in order to identify it ${ }^{(5)}$.

Most of the cases are inherited from dominant autosomal (types I-V), although there are variants of autosomal recessive transmission (some rare cases of type III and types VII-VIII), and possibility of de novo mutation occurrence ${ }^{(4,6)}$.

The majority of patients have genetic mutation in one of the two genes that code a chain of collagen type I. The genes COL1A1 or COL1A2 that occur in types I to $\mathrm{IV}^{(1)}$. These mutations reduce the amount of collagen type I produced by the organism, leading to bone fragility. Not all cases present mutations in these genes, as in types V-VIII that mutations are not found ${ }^{(6)}$.

Clinical forms of the disease vary from mild (OI type I) or moderate (OI type V-VII) to severe features (OI types III and IV), or even lethal in perinatal period (type II). Clinical picture includes multiple fractures in the absence of trauma, bone deformities, blue sclerotics, dentinogenesis imperfecta, and from puberty conductive or mixed deafness ${ }^{(2,6)}$.

Prenatal diagnosis may be performed in risk gestation by chorionic villus sampling with analysis of collagen synthesis by fetal cells between 10 and 12 weeks of gestational age, or even by ultrasonography to identify bone fractures ${ }^{(6-7)}$. The diagnosis after birth is the main function of clinical picture of the patient, with family history analysis and radiological features or when required biochemical or genetic tests ${ }^{(8)}$.

Nowadays, treatment is based on bifosfonates that may provide significant improvement to patient, reducing pain, number of fractures and improving mobility. In addition, physical therapy, rehabilitation and orthopedic surgery are also therapeutic options ${ }^{(9)}$.

\section{CASE DESCRIPTION}

We report a case of a newborn, five days old, female, weighing 2,460 g, black race, gestational age not informed, eutocic delivery at the Hospital, referred from a public maternity. The child's mother did not have prenatal follow-up and reported non-existence of disease in the family. The child was admitted to the hospital in agonal state, pale mucosa, acute respiratory failure, respiratory rate at $66 \mathrm{rpm}$, marked intercostal retractions, sterna retraction, and intense cyanosis by severe hypoxemia. The child presented deformity, short and curved extremities. Subcutaneous crepitation of the patellar region and medium third of tibia and fibula was observed. The neonate's head seemed disproportionate in relation to her body, she had low set ears and blue sclerotics (blue halo). The heart rate was 146 bpm, audible systolic murmur in all auscultation sites, ictus cordis and fremitus of $++++++/ 6$, abdominal bloating and hepatomegaly of $4 \mathrm{~cm}$ were presented.

Basic life support maneuvers were performed, including oral-tracheal intubation and transference to Neonate Intensive Care Unit. After that, the child was submitted to continuous ventilatory support.

The hypotheses of OI was conceived and the following complemented tests were requested:

- X-ray of long bones. Radiologic imaging test showed multiple fractures of clavicle, humerus, ratio, patellar, femur, tibia and fibula (Figure 1 and 2);

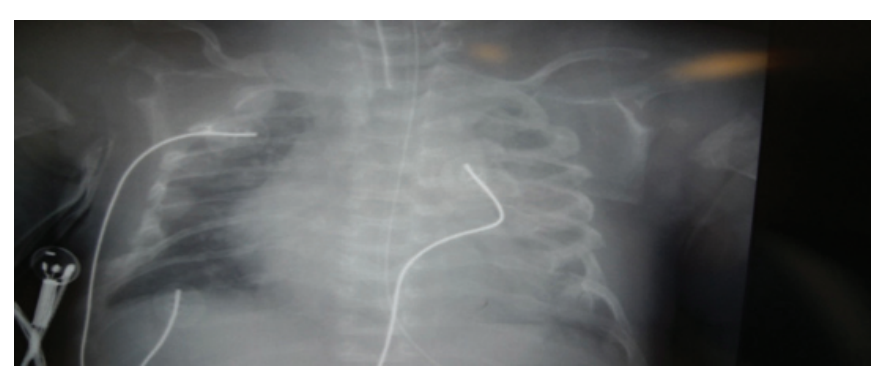

Figure 1. Decubitus AP chest $\mathrm{X}$-ray showing pulmonary impairment due to cardiogenic congestion. Increase in cardiac area for right cage. Curved fractures of right clavicular bone

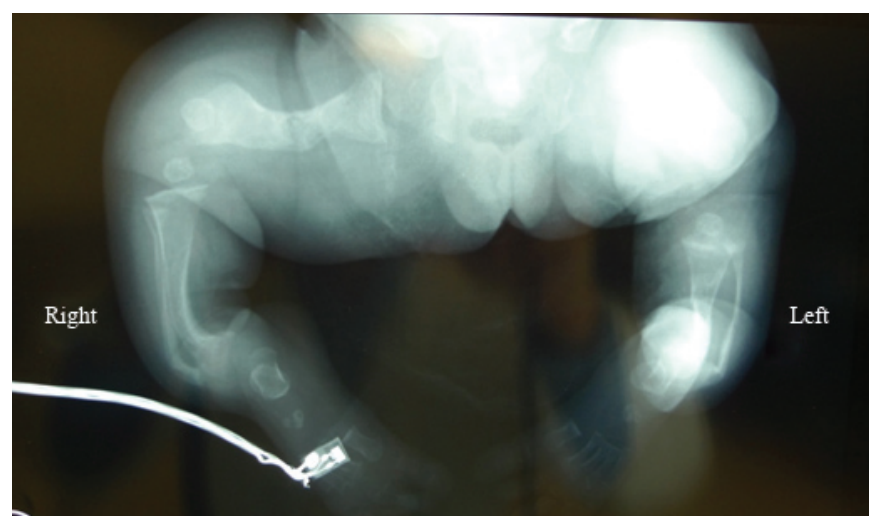

Figure 2. Inferior limbs X-ray showing multiple fractures of tibia, fibula and bilateral femur with curved bones.

- Doppler echocardiography. Color in situs solitus, good concordance of atrioventricular and lateral ventricle, right cavities overriding the left one, integrity of ventricular septal. Ostium Secundum auricular septal defect of about $3 \mathrm{~mm}$ with left-toright shunt and thickness of sigmoid pulmonary vein. The pulmonary artery stem was slightly dilated. Normal pulmonary and aortic transvalvular gradient, and systolic and diastolic functions of the left ventricle were sustained without significant morphofunctional changes of valves (Figure 3). Skull X-ray was not performed. 


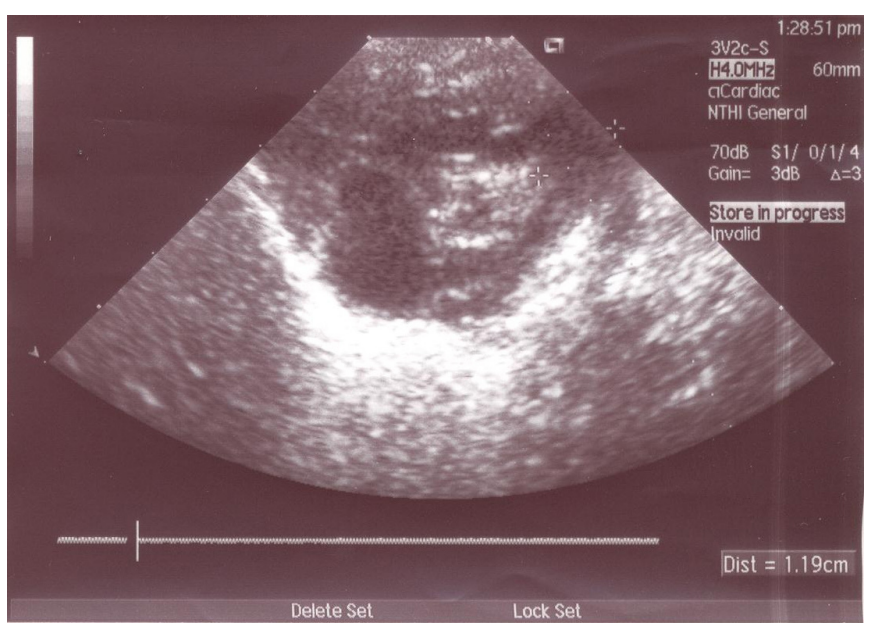

Figure 3. Ostium Secundum atrial septal defect and increase of $A D$ and pulmonary artery trunk dilated.

We used disodium pamidronate for the specific treatment of OI. The newborn was submitted to advanced life support for cardiogenic shock with vasoactive drugs and mild sedation to perform mechanical ventilator support more comfortable. She was totally dependent on noradrenaline associated to dobutamine and vasoactive drugs to reduce pre and post-loading.

The most concerning aspect, which was subject of intense surveillance by a multi-professional group, was related to avoiding new fractures to the child during endotracheal suction and decubitus changes. In addition, the child received enteral feeding with calcium and vitamin $\mathrm{D}$.

The newborn presented pneumonia while on mechanical ventilation and received antimicrobial agent according to the culture performed. There was response to diuretic and colloid therapy which aimed to reduce the observed anasarca. However, general conditions progressively aggravated and the newborn died at 24 days of life.

\section{DISCUSSION}

This case showed characteristics of OI type II, such as: evident abnormalities at birth, sclerotics with blue halo, head disproportionate to the body, short and curved extremities, and several fractures which resulted in perinatal death.

The death by cardiorespiratory failure is also considered to pertain to OI type $\mathrm{II}^{(10)}$. These abnormalities are linked to changes of collagen type I, which is the largest structural protein of bones, ligaments, tendons, skin, sclerotic, dentin, blood vessels and hollow organs ${ }^{(11,12)}$.

Normally, pulmonary involvement results from small rib cage and/or rib fracture ${ }^{(10)}$.
A data that raised our attention in this case was the presence of interatrial communication (IC) with integrity of aortic and mitral valve. The most frequent cardiac abnormality in these cases is related to left structures, and to date there is only one case that describes right heart involvement ${ }^{(13)}$. The left heart signed anomalies are: dilated aortic trunk in $12 \%$ according to a series of cases described by Hortop et al. ${ }^{(14)}$, aortic regurgitation followed by mitral valve prolapse, and more rarely aortic dissection, aneurysm of sinus of Valsalva and coronary artery dissection ${ }^{(13)}$.

The occurrence of IC was not previously signed as part of cardiac abnormalities present in OI, and from the best of our knowledge this is the first time it has been found.

Skull radiography not performed to register the existence of wormian bones, do not invalidate the hypothesis that this is a case of OI type II, because other facts of great importance support our hypothesis.

Due to the absence of family history of this disease, it is probably a sporadic mutation.

\section{REFERENCES}

1. Forin V. [Osteogenesis imperfecta]. Presse Med. 2007;36(12 Pt 2):1787-93. French.

2. Sillence DO, Senn A, Danks DM. Genetic heterogeneity in osteogenesis imperfecta. J Med Genet. 1979;16(2):101-16.

3. Fano V, Rodríguez Celin M, Del Pino M, Buceta S, Obregón MG, Primomo Cet al. [Osteogenesis imperfecta. Clinical, functional and multidisciplinary evaluation of 65 patients]. An Pediatr (Barc). $2010 ; 72(5): 324-30$.Spanish.

4. Van Dijk FS, Pals G, Van Rijn RR, Nikkels PG, Cobben JM. Classification of Osteogenesis imperfecta revisited. Eur J Med Genet. 2010;53(1):1-5.

5. Steiner RD, Pepin M, Byers PH. Studies of collagen synthesis and structure in the differentiation of child abuse from osteogenesis imperfecta. J Pediatr. 1996;128(4):542-7.

6. Steiner RD, Pepin MG, Byers PH. Osteogenesis imperfecta. In: Pagon RA, Bird TC, Dolan CR, Stephens K, editors. GeneReviews [Internet]. Seattle (WA): University of Washington, Seattle; 2005

7. Morgan JA, Marcus PS. Prenatal diagnosis and management of intrauterine fracture. Obstet Gynecol Surv. 2010;65(4):249-59.

8. Burnei G, Vlad C, Georgescu I, Gavriliu TS, Dan D. Osteogenesis imperfecta: diagnosis and treatment. J Am Acad Orthop Surg. 2008;16(6):356-66.

9. Rauch F, Glorieux FH. Osteogenesis imperfecta, current and future medical treatment. Am J Med Genet C Semin Med Genet. 2005 ;139C(1):31-7.

10. Bonita RE, Cohen IS, Berko BA. Valvular heart disease in osteogenesis imperfecta: presentation of a case and review of the literature. Echocardiography. 2010;27(1):69-73.

11. Strevel EL, Papaioannou A, Adachi JD, McNamara M. Case report: osteogenesis imperfecta elusive cause of fractures. Can Fam Physician. 2005;51(12):1655-7.

12. Chan TF, Poon A, Basu A, Addleman NR, Chen J, Phong A, et al. Natural variation in four human collagen genes across an ethnically diverse population. Genomics. 2008;91 (4):307-14.

13. Khashu M, Pelligra G, Sandor G, Singh AJ: Right sided cardiac involvement inosteogenesis imperfecta. J Heart Valve Dis. 2006;15(4):588-90.

14. Hortop J, Tsipouras P, Hanley J, Maron BJ, Shapiro JR. Cardiovascular involvement in osteogenesis imperfecta. Circulation. 1986;73(1):54-61 